\title{
Paulo Freire e a gestão da educação: análise das pesquisas em três programas de pós-graduação do Brasil
}

Paulo Freire and educational management: analysis of research in three brazilian graduate programs Paulo Freire y la gestión de la educación: análisis de la investigación en tres posgrados en Brasil

LÚCIO JORGE HAMMES

http://orcid.org/0000-0003-0658-4628

Universidade Federal do Pampa

Programa de Pós-graduação em Educação

Departamento de Educação Jaguarão, RS, Brasil

ITAMAR LUÍS HAMMES

http://orcid.org/0000-0002-3532-5011 Instituto Federal de Educação, Ciência e Tecnologia Sul-riograndense Programa de Pós-graduação em Educação Profissional e Tecnológica

Departamento de Educação Lajeado, RS, Brasil

JAIME JOSÉ ZITKOSKI

https://orcid.org/0000-0003-1266-2039 Universidade Federal do Rio Grande do Sul Programa de Pós-graduação em Educação

Departamento de Educação

Porto Alegre, RS, Brasil

\begin{abstract}
Resumo: A gestão educacional tem em Paulo Freire referência destacada na academia e contribui para o desenvolvimento de pesquisas na pós-graduação. Partindo dos dados coletados nos trabalhos de conclusão de três programas de Pós-Graduação do Rio Grande do Sul, fez-se uma abordagem qualitativa, na perspectiva metodológica da abordagem da análise documental. Os resultados apontaram para a importância dessas pesquisas para superar a educação bancária e compreender a gestão das práticas educativas e das políticas públicas, tendo presente a perspectiva interdisciplinar da obra de Paulo Freire. Esse diálogo, constatado nas pesquisas, pode ajudar a qualificar a gestão educacional na ação educativa e na gestão das redes de ensino.
\end{abstract}

Palavras-chave: Paulo Freire. Gestão educacional. Pesquisas. Pós-graduação.. 


\begin{abstract}
Educational management has a prominent reference in Paulo Freire in the academy and contributes to the development of research in graduate studies. Based on the data collected in conclusion works of three Graduate Programs in Rio Grande do Sul, a qualitative approach was made, in the methodological perspective of the document analysis approach. The results pointed to the importance of these researches to overcome banking education and to understand the management of educational practices and public policies, bearing in mind the interdisciplinary perspective of Paulo Freire's work. This dialogue, verified in the researches, can belp to qualify educational management in the educational action and the management of the education networks.
\end{abstract}

Keywords: Paulo Freire; Educational management; Researches; Graduate studies.

Resumen: La gestión educativa tiene un referente destacado en Paulo Freire en el ámbito académico y contribuye al desarrollo de la investigación de posgrado. A partir de los datos recogidos en los trabajos de conclusión de tres Posgrados en Rio Grande do Sul, se realizó un abordaje cualitativo, en la perspectiva metodológica del enfoque de análisis documental. Los resultados señalaron la importancia de estas investigaciones para superar la educación bancaria y comprender la gestión de las prácticas educativas y las políticas públicas, teniendo en cuenta la perspectiva interdisciplinar del trabajo de Paulo Freire. Este diálogo, verificado en las investigaciones, puede ayudar a capacitar la gestión educativa en la acción educativa y en la gestión de las redes educativas.

Palabras-clave: Paulo Freire; Gestión educativa; Investigaciones; Posgrado.

\title{
INTRODUÇÃO
}

Esse artigo tem por objetivo analisar as repercussões das pesquisas realizadas em três programas de pós-graduação em Educação (PPGEs) que se inspiram na obra de Paulo Freire. Essas pesquisas revelam que os discentes dos programas da Universidade Federal do Rio Grande do Sul (UFRGS), do Instituto Federal Sul-Rio-Grandense (IFSul) e da Universidade Federal do Pampa (Unipampa) revelam ter proximidade com leituras e a pedagogia freiriana, pois em seus trabalhos de conclusão trazem Paulo Freire como referência central, ou enquanto um dos autores que dialogam com a pesquisa.

Como a obra de Paulo Freire trata basicamente da educação, as pesquisas dos pós-graduandos encontram apoio para desenvolver aprofundamentos, qualificando sua prática de gestão da ação educativa ou encontram sustento para melhorar a gestão das redes e das políticas de educação.

O recorte temporal de nossa análise está delimitado nos seguintes períodos: de 2014 a 2020, no PPGE da Unipampa; no período de 1995 a 2020, no PPGE da UFRGS; e de 2013 a 2020, no PPGE do IFSul. Essa delimitação diz respeito a dois critérios, a saber: a) por razões dos trabalhos estarem disponíveis 
on-line nos repositórios dos PPGEs e b) pela diferença do tempo de criação de cada um dos programas - inaugurado em 1970 na UFRGS, em 2012 na Unipampa, e em 2013 no IFSul.

Destacamos que a razão principal da importante presença de Paulo Freire no universo de nossa análise reside na perspectiva interdisciplinar de sua obra. Freire é hoje o autor brasileiro mais lido e citado mundialmente na área das Ciências Humanas e Sociais, sendo o terceiro autor mais citado nesse campo científico, à frente de autores como L. S. Vygotsky, Karl Marx ou Michel Foucault. Conforme Green (2016), os autores mais citados na academia são, em primeiro lugar, Thomas S. Kuhn, com "As estruturas das revoluções científicas", de 1962; seguida de Everett Rogers, com "Diffusion of innovations", também de 1962; e, em terceiro lugar, Paulo Freire, com "Pedagogia do oprimido", publicada em 1968.

O reconhecimento da academia à obra de Paulo Freire revela a grande abertura e interconexão de seu pensamento com os temas centrais da contemporaneidade. E, como a área da educação é interdisciplinar por natureza, Paulo Freire nos inspira a pensar criticamente várias temáticas, como: educação de jovens e adultos, educação popular, meio ambiente, formação de professores, gestão democrática, políticas públicas, didática e métodos alternativos, direitos humanos, entre outros.

Este artigo tem por base uma pesquisa qualitativa que utilizou a abordagem da análise documental, conforme propõe Severino (2007, p. 122): “tem-se como fonte documentos no sentido amplo, ou seja, não só documentos impressos, mas [...] documentos, tais como jornais, fotos, filmes, gravações, documentos legais." Seguindo essas formulações, podem ser considerados documentos úteis para o desenvolvimento de investigações que utilizam a abordagem citada, os relatórios de diferentes ordens e instituições, os documentos legais, divulgações jornalísticas, e-mails, cartas, filmes, gravações, fotografias, entre outros que se mostrarem úteis para o alcance do objetivo enunciado.

Nessa perspectiva, o mapeamento iniciou com o regimento do PPGE Mestrado Profissional (2011) da Unipampa e, em um segundo momento, com os dados das pesquisas realizadas no PPGE/UFRGS. Os dados foram trabalhados pela análise textual discursiva, proposta por Moraes (2003), constituída com base na análise de conteúdo de Bardin (1977), mas também utilizando elementos de análise do discurso. Esse modelo de análise foi descrito por Moraes (2003, p. 202) como "uma metodologia na qual, a partir de um conjunto de textos ou documentos, produz-se um metatexto, descrevendo e interpretando sentidos e significados que o analista constrói ou elabora a partir do referido corpus." 
As análises efetivamente ficaram mais centradas nos Relatórios Críticos Reflexivos da Unipampa, nas teses e dissertações do PPGE/UFRGS e na análise das dissertações do PPGE/IFSul. Nesse universo, foram avaliados 276 trabalhos de pesquisa final de mestrado e doutorado.

Destacamos que a presença de Paulo Freire nos três PPGEs não é algo apenas pontual, mas articula-se com uma rede de pesquisadores e lideranças educacionais que se formou no Rio Grande do Sul a partir do Fórum Paulo Freire, que em 2021 chega à sua $22^{a}$ edição e, igualmente, com os seminários anuais: Diálogos com Paulo Freire, já na $10^{\mathrm{a}}$ edição. Vários alunos e professores ligados aos três PPGEs participam com trabalhos e também atuam na organização desses eventos.

Esse movimento orgânico inspirado na pedagogia freiriana revela uma quantidade e qualidade nas produções acadêmicas, não só nas dissertações e teses, mas também na produção de livros e artigos para periódicos. Portanto, a obra de Freire é destacadamente fecunda no contexto da formação de educadores em nosso estado, capacitando-o para desenvolver a gestão de unidades escolares, especialmente relacionadas às práticas educativas, como também à gestão das redes e das políticas educacionais.

\section{A PRESENÇA DE PAULO FREIRE NO PPGE/IFSUL - MESTRADO PROFISSIONAL EM EDUCAÇÃO E TECNOLOGIA}

O Mestrado Profissional em Educação e Tecnologia (MPET-IFSul) iniciou suas atividades em 2012. Sua aprovação, em 2011, foi a culminância de esforços coletivos produzidos com foco na ideia de uma educação que não dissocia ações de ensino, pesquisa e extensão, "atuando na formação de professores, com o intuito de participar significativamente do desenvolvimento social e regional" (IFSUL, 2021). O programa remonta inicialmente a uma necessidade interna de formação pedagógica de docentes para as disciplinas do Currículo da Educação Profissional do nível técnico, a uma discussão qualificada da relação entre educação e tecnologia, configurando-se inicialmente em Programa Especial de Formação Pedagógica, cursos superiores de formação tecnológica e Pós-Graduação Lato Sensu em Educação Tecnológica. Dessa forma, as áreas de educação e tecnologia permeavam conjuntamente a dimensão da formação em nível stricto sensu.

A área de concentração do Mestrado Profissional é a Educação, e desenvolve estudos "focando nas mediações que se realizam para que o processo educacional seja desenvolvido, seja através de uma mediação linguística, estética, tecnológica, pedagógica, entre outras" (IFSUL, 2019). Os objetivos do curso são: 
Formar profissionais qualificados para o exercício das atividades de ensino, pesquisa e extensão, a partir de saberes ético-estéticos, docentes e tecnológicos, proporcionando o desenvolvimento da produção de conhecimento no campo da educação e das tecnologias educacionais, visando atender demandas sociais, organizacionais e/ou profissionais da educação e da tecnologia, com o intuito de prover ações de inserção e de intervenção no contexto social. Articular a formação ao campo profissional da educação, conforme resolução da CAPES, no que tange os Mestrados Profissionais, como forma de desenvolver conhecimento para a sociedade, atendendo demandas específicas e de arranjos produtivos com vistas ao desenvolvimento nacional, regional e/ou local. Desenvolver a capacitação profissional dos profissionais da área de educação, pelo provimento de uma articulação integrada entre a formação docente e as tecnologias educacionais, compondo propostas de pesquisas aplicadas que possam produzir a inovação e a qualificação contínua da educação básica. (IFSUL, 2019).

O programa deseja "formar profissionais-pesquisadores a partir de saberes ético-estéticos, docentes e tecnológicos, com vistas à atuação no campo da educação básica, capazes de realizar intervenções em suas próprias práticas, bem como no contexto social no qual está inserido" (IFSUL, 2019). As linhas de pesquisa são: a) Inserção social: trabalho, cultura e tecnologias na educação básica; b) Intervenções no espaço-tempo da educação básica: filosofia, arte e tecnologia; c) Tecnologias aplicadas à educação básica: processos de formação.

O curso exige um mínimo de 24 créditos, entre obrigatórios (que compõem a formação básica profissional) e eletivos. O currículo está organizado por quatro disciplinas obrigatórias, responsáveis por uma formação de base na área da educação e por seminários eletivos, que semestralmente são atualizados na relação direta com o estado da arte das pesquisas dos professores-pesquisadores responsáveis. $\mathrm{O}$ aluno necessita cumprir a etapa de defesa de qualificação de seu projeto de pesquisa, preferencialmente, antes do início do terceiro semestre, ou seja, entre os primeiros 12 meses de curso, visto que o tempo máximo para a defesa da dissertação é de 24 meses (IFSUL, 2019).

O programa se orgulha pela forma de integração social, na medida em que desenvolve pesquisa aplicada com capacidade de intervenção no contexto escolar da educação básica. As pesquisas focam especialmente nas angústias, percepções e necessidades dos profissionais desse contexto, que trazem suas experiências anteriores, gerando conhecimentos e produtos diretamente aplicáveis ao seu fazer profissional. Ao aliar educação e tecnologia, é possível fazer diferença nesse contexto, como forma de propor novas ações de inserção (IFSUL, 2021).

O MPET já titulou mais de 100 mestres. No repositório, encontramos 108 dissertações, realizadas entre os anos 2012 e 2019. Segundo o site oficial (IFSUL, 2021), desde o primeiro processo seletivo até o último, que se encontra em curso, tem-se uma taxa média em torno de 500 candidatos inscritos por concurso, que 
disputam em torno de 25 vagas. É importante ressaltar também que em 2020 o PPGE recebeu a aprovação da Coordenação de Aperfeiçoamento de Pessoal de Nível Superior (Capes) para implantar o curso de Doutorado Profissional em Educação e Tecnologia.

Em relação à presença de Paulo Freire no PPGE, não se percebeu nenhuma menção nos documentos do programa. No entanto, quando do recurso às pesquisas desenvolvidas, percebeu-se que ele está entre os autores mais citados. Das 108 pesquisas encontradas no repositório, realizadas entre 2013 e 2019, 31 dissertações recorrem a Paulo Freire de uma forma ou de outra. Em 3 dissertações, Paulo Freire aparece como referência central, sendo citado mais de 8 vezes e tendo duas ou mais obras citadas nas referências bibliográficas; em 28 dissertações, o autor é citado como referência de apoio, como epígrafe, suporte na metodologia ou mesmo como fundamento teórico educacional.

Tabela 2 - Paulo Freire nas dissertações do PPGE/IFSul

\begin{tabular}{|c|c|c|c|c|c|c|c|c|c|}
\hline & 2013 & 2014 & 2015 & 2016 & 2017 & 2018 & 2019 & 2020 & Total \\
\hline Referência central & & & & 1 & 1 & 1 & & & 3 \\
\hline Referência de apoio & 1 & 9 & 7 & 1 & 8 & 2 & & & 28 \\
\hline Não referenciado & 2 & 12 & 11 & 20 & 17 & 13 & 2 & & 77 \\
\hline Total de RCR & 3 & 21 & 18 & 22 & 26 & 16 & 2 & & 108 \\
\hline
\end{tabular}

Fonte: Dissertações defendidas no PPGE/IFSul, disponíveis no site do curso.

A tabela acima procura mostrar a presença de Paulo Freire nas dissertações defendidas no PPGEDU do IFSul entre os anos 2012 e 2019, que são as dissertações encontradas no Repositório do IFSul, totalizando 108 trabalhos. Das 108 dissertações, 3 tomam Paulo Freire como referência central; 28 como referência de apoio; e 77 não contemplam Paulo Freire em seus trabalhos.

Das pesquisas que tomam Paulo Freire como autor central, as obras mais citadas são "Pedagogia da autonomia" e "Pedagogia do oprimido". São citadas também: "A importância do ato de ler", "Pedagogia da esperança", "Educação na cidade" e "Educação e mudança". Nessas pesquisas, Paulo Freire aparece como pensador da educação na perspectiva histórico-crítica, ao lado de Gramsci, Saviani, Marx, Pistrak, entre outros.

Do conjunto dos trabalhos, 28 dissertações têm Freire como referência de apoio. Percebe-se o recurso a Paulo Freire como um autor importante e decisivo na justificação das práticas educativas, porém, não central na proposta 
metodológica. Os autores destacam a educação problematizadora, que pergunta e investiga, a ação e reflexão, a proposta dialógica, a crítica à educação bancária e a defesa de uma concepção de educação libertadora.

\section{AS PESQUISAS INSPIRADAS EM PAULO FREIRE NO PPGE/UNIPAMPA}

O Mestrado Profissional em Educação pretende ser um espaço para oportunizar que as demandas se encontrem com profissionais interessados em atendê-las, ou seja, com quem pode fazer a mediação entre o desejo de solução de problemas existentes e as diferentes formas de abordá-los. Dessa forma, acontece o encontro entre o conhecimento da realidade e o conhecimento científico, entre o saber da experiência e a rigorosidade metódica. A formação permanente consiste nesse entrelaçamento entre a teoria e prática, no encontro entre o cotidiano e a formulação teórica.

O curso foi organizado em quatro semestres, com atividades quinzenais, concentradas em quintas-feiras à noite, nas sextas-feiras em períodos diurno e noturno, e aos sábados, diurno. Essa concentração de períodos quinzenais na oferta tem a finalidade de possibilitar a melhor participação dos estudantes oriundos da rede pública da educação básica, profissionais em exercício, favorecendo para os deslocamentos destes para os encontros de estudos.

A Portaria Normativa $\mathrm{n}^{\circ}$ 17, de 2009, da Capes (BRASIL, 2009, p. 21), em seu art. $4^{\circ}$, destaca como um dos objetivos do mestrado profissional: "capacitar profissionais qualificados para o exercício da prática profissional avançada e transformadora de procedimentos, visando atender demandas sociais, organizacionais ou profissionais e do mercado de trabalho." Assim, este PPGE organizou os editais para processos seletivos com oferta de vagas exclusivas para professores que atuam na educação básica da rede pública.

O formato do trabalho de conclusão de curso (TCC) é utilizado com os itens necessários para a composição de um relatório de pesquisa, que no PPGE é denominado Relatório Crítico-Reflexivo (RCR). Em seu art. $7^{\circ}$, inciso VIII, $₫ 3^{\circ}$, a Capes orienta que "o trabalho de conclusão final do curso poderá ser apresentado em diferentes formatos [...] de acordo com a natureza da área e a finalidade do curso, desde que previamente propostos e aprovados pela Capes." (BRASIL, 2009). A partir dessa orientação, o PPGE adota como trabalho de conclusão final o RCR, resultante da consecução de três etapas. 
12. Elaboração de um Projeto de Intervenção no espaço institucional de atuação do pós-graduando, sob orientação de Docente Permanente (Orientador credenciado) do Programa e com avaliação final mediante apresentação pública a uma banca constituída de pelo menos dois docentes da Unipampa, sendo um deles do próprio Programa. $2^{\text {a }}$. Execução do Projeto de Intervenção aprovado, com produção de Relatório Final (crítico-reflexivo), sob supervisão do Orientador; $3^{\mathrm{a}}$ Apresentação do Relatório Final do Projeto de Intervenção, para avaliação de banca constituída por pelo menos três docentes: um docente permanente (Orientador credenciado), um docente do próprio Programa e um professor-doutor de outra instituição. (UNIPAMPA, 2018).

O curso de mestrado oportuniza a professores, em efetivo exercício, com vínculo com a rede pública de ensino, interessados na gestão da educação, revisitar criticamente o aparato teórico-metodológico, que tem fundamentado o planejamento de suas práticas, na direção de capacitá-los à produção de conhecimentos geradores de novas rotinas de trabalho.

As pesquisas e a execução dos projetos de intervenção dos mestrandos têm produzido repercussões na região, atendendo profissionais que atuam nas unidades escolares, nas secretarias municipais de educação, nas escolas e nas coordenadorias. Os TCC produzidos a partir das intervenções nas redes de educação foram analisados a partir de categorias centrais da educação freiriana.

Analisamos aqui os RCR dos alunos que defenderam seu trabalho final nos anos de 2012 a 2020. Como as entradas são anuais, temos até agora 8 entradas (2012 a 2019). O curso tem previsão de conclusão de 2 anos, podendo terminar um pouco antes ou um pouco depois desse prazo. O critério adotado consistia em observar as citações sobre Paulo Freire, tendo como base "referência central" ou "referência de apoio". Para ser referência central, a citação a Freire deveria estar presente como base da construção da metodologia do trabalho e ser citado mais de 10 vezes, e com mais que duas obras citadas nas referências. Já a referência de apoio é aquela citação em que Paulo Freire aparece no relatório, não sendo base do trabalho. Assim temos:

Tabela 2 - Paulo Freire nos RCRs da Unipampa

\begin{tabular}{|c|c|c|c|c|c|c|c|c|c|}
\hline & 2012 & 2013 & 2024 & 2015 & 2016 & 2017 & 2018 & Total & Total \\
\hline Referência central & 3 & 12 & 5 & 5 & 7 & 10 & 2 & 44 & 3 \\
\hline Referência de apoio & 4 & 10 & 11 & 6 & 6 & 5 & 1 & 43 & 28 \\
\hline Não referenciado & 3 & 6 & 5 & 4 & 1 & 7 & 3 & 29 & 77 \\
\hline Total de RCR & 10 & 28 & 21 & 15 & 14 & 22 & 6 & 116 & 108 \\
\hline
\end{tabular}

Fonte: RCRs do PPGE, organizados por ano de entrada. Disponíveis no site do curso. 
A tabela apresenta um total de 116 RCRs defendidos na Unipampa por alunos que entraram no curso a partir de 2012, quando foi iniciado o Mestrado em Educação da instituição. Desse total, 44 têm Paulo Freire como referência central; 43, como referência de apoio; e 29 não contemplavam o autor em seus trabalhos. Todos os relatórios estão disponíveis no portal do curso ${ }^{1}$.

Diversos trabalhos citam Freire como epígrafe, caracterizando o trabalho que desenvolvem:

Gosto de ser gente porque, mesmo sabendo que as condições materiais, econômicas, sociais e políticas, culturais e ideológicas em que nos achamos geram quase sempre barreiras de difícil superação para o cumprimento da nossa tarefa histórica de mudar o mundo, sei também que os obstáculos não se eternizam. (FREIRE, 2002, p. 22).

Outros citam a referência como base metodológica no próprio resumo: "Freire, Lüdke, Damiani, Fazenda, André, Mello, Veiga, Nóvoa, entre outros serviram como fundamentação teórico-conceitual e teórico-metodológica; além do ordenamento constitucional, legal e normativo." (COMIN, 2016, p. 9). Alguns já trazem a proposta na introdução do trabalho com sua referência:

O presente trabalho parte do contexto do Mestre Paulo Freire $(1988,1996)$ de considerar a importância de uma educação ambiental transformadora e cidadã, no sentido de transformação social de entender a educação como um processo sociopolítico, libertar o ser humano das alienações oportunizando-lhe autonomia e ter consciência social. (ROCHA, 2016, p. 10).

Entre os trabalhos que têm Paulo Freire como referência central, a obra mais referenciada é "Pedagogia da autonomia" (2002), citada em 45 trabalhos, seguida da "Pedagogia do oprimido" (1983), presente em 40. "Educação como prática da liberdade" (2011) está presente em 20 obras; "Pedagogia da esperança" (1997), em 10; "Pedagogia da indignação" (2000), em 13; "Educação e mudança" (2010) tem 9 citações; "A importância do ato de ler" (1989); e "Conscientização: teoria e prática da liberdade" (1996), citada 4 vezes.

Do conjunto dos trabalhos, 43 têm Freire como referência de apoio. Estes se referem a ele como autor importante, mas não central, em sua proposta de metodologia. Os autores dos trabalhos afirmam que:

1 Disponível em: http://cursos.unipampa.edu.br/cursos/ppgedu/dissertacoes/. Acesso em: 10 mar. 2021. 
O saber dialógico mostra, de forma problemática, um indivíduo ou circunstâncias existenciais do grupo em relação ao contexto sócio-político mais amplo. É precisamente esta perspectiva freiriana que orientou essa ação de intervenção entre orientador, educadores e alunos, sendo a proposta uma forma de resolução da violência. É no diálogo permanente, crítico/reflexivo, que se construiu as estratégias de resolução e a proposta de intervenção coletiva. (MELGAR, 2014, p. 21).

Os autores trazem os ensinamentos de Paulo Freire para as suas pesquisas, como referências importantes, com os quais qualificam os seus trabalhos. Embora não centrais, a lições de Freire são importantes para a organização e interpretação dos dados das pesquisas.

\section{A PRESENÇA DE PAULO FREIRE NAS PESQUISAS NO PPGEDU-UFRGS}

As análises que seguem sobre a presença de Freire nas pesquisas do PPGE/UFRGS são referentes ao período de 1995 a 2020, considerando as dissertações e teses defendidas nesse período, que tiveram a obra de Paulo Freire como referencial central, ou enquanto um dos autores importantes em seu referencial teórico.

Encontramos através dos registros no $\mathrm{LUME}^{2}, 52$ trabalhos que revelam uma presença forte da obra de Freire enquanto referencial teórico em diálogo com a análise dos dados. São 35 dissertações de mestrado e 17 teses de doutorado, nas quais a obra de Paulo Freire é central ou emerge entre diálogo fecundo com outros autores.

O que nos despertou a atenção é a diversidade das temáticas e das diferentes linhas de pesquisa nas quais Freire circula no PPGE/UFRGS.

Os temas e áreas de estudo vão desde a informática, passando pela formação de professores e educação infantil, chegando à discussão da educação popular e educação de jovens e adultos. Esse dado mostra a grande abertura da pedagogia freiriana e sua base interdisciplinar na forma de trabalhar as questões da formação e os temas centrais da área educacional. Talvez seja esse o fato de que a obra de Freire continua a despertar ainda hoje tanta curiosidade e interesse. Ou seja, Paulo Freire continua a ser um autor da atualidade, mesmo que precisemos situar sua obra, em sua fase mais madura, nos anos 1990. 
A seguir, passamos a relacionar alguns títulos de teses e dissertações que expressam a reflexão que fizemos acima:

1. Jürgen Habermas, Paulo Freire e a crítica à cidadania como horizonte educacional: uma proposta de revivificação da educação popular ancorada no conceito de sujeito social;

2. Instituto de Educação Josué de Castro: Paulo Freire e a "escola diferente";

3. A educação para a autonomia em Immanuel Kant e Paulo Freire;

4. Aprendendo a ler/ver televisão na Educação de Jovens e Adultos;

5. Educação técnico-científica emancipatória nos IFETs: um olhar através de Habermas e Freire;

6. Paulo Freire e Michel Serres: aproximações na perspectiva interdisciplinar num diálogo a múltiplas vozes;

7. Informática educativa no Rio Grande do Sul: um estudo das possibilidades de inclusão em uma escola pública;

8. Partilhando olhares: perspectivas da arte na educação de jovens e adultos do CMET Paulo Freire;

9. A formação dos(as) educadores(as) a partir da práxis: um estudo de caso da AEPPA;

10. Da intenção à Ação: avanços e retrocessos na Educação de Jovens e Adultos na Rede Estadual do RS no período de 1999 a 2008.

Os títulos apresentados (que são apenas uma amostra do universo definido de 52 trabalhos já referidos acima) revelam a diversidade de temas e áreas do campo educacional em que as leituras de Freire ajudam a refletir e problematizar o debate da pesquisa em educação. Mesmo que, em certos casos, a sua obra não seja a referência central, nota-se um diálogo fecundo na forma como seu pensamento se relaciona com a discussão pedagógico-formativa e com as alternativas práticas de busca de soluções a certos gargalos nas diferentes áreas da educação.

Nesse contexto, são diferentes linhas de pesquisa do PPGE que trabalham com os referenciais freirianos, e a forma de abordá-los também é diferenciada.

As linhas de pesquisa também foram sendo modificadas com o tempo. Um dos pioneiros que trabalhou com a obra de Paulo Freire é o Prof. Balduino Andreola, que orientou várias dissertações e teses nessa perspectiva na área de Educação Popular e EJA. O saudoso Prof. Nilton Fischer também trabalhou com seus orientandos na década de 1990, e nos anos 2000, com o referencial freiriano. Os professores do grupo do TAMSE também orientaram várias pesquisas se referenciando na obra do autor. E a linha de pesquisa "Universidade - Teoria e Prática" tem marcado presença sobre diferentes pesquisas que se fundamentaram 
na obra de Freire. Além dessas mencionadas, atualmente as linhas "Educação, Culturas e Humanidades" e "Educação e Infâncias" apresentam uma importante presença da pedagogia freiriana em suas pesquisas.

Além desses grupos relacionados, destacam-se diferentes trabalhos do PPGE em outras linhas de pesquisa que dialogaram com a obra de Paulo Freire, tais como: políticas públicas, educação e formação do sujeito, informática na educação, entre outras.

As pesquisas acessadas nesse período, principalmente as 52 teses e dissertações consultadas, traduzem uma presença importante do referencial freiriano no PPGE/UFRGS, e esse fato também está relacionado com as articulações e o trabalho em rede com os diferentes grupos de pesquisadores e lideranças educacionais que se organizam a partir do Fórum Paulo Freire, no Rio Grande do Sul, e com as edições do evento: Diálogos com Paulo Freire, também organizado por várias instituições de ensino superior em nosso estado. Essa rede de educadores, que se mantêm mobilizados há mais de 20 anos, resulta do trabalho solidário e colaborativo que já possibilitou 22 edições de encontros anuais, ininterruptos, de Fóruns Paulo Freire no estado, a partir dos quais muitas produções conjuntas vêm alimentando e frutificando as experiências de educadoras e educadores comprometidos com a humanização dos processos formativos.

Enquanto fruto dessa rede freiriana, além de outras produções importantes, destacamos o "Dicionário Paulo Freire" e vários livros em forma de coletâneas, e grupos de pesquisa orgânicos, em diferentes universidades de nosso estado.

Esse movimento de pesquisas e produções acadêmicas que têm na obra de Freire um dos aportes teóricos, certamente impulsiona políticas de formação e projetos de educação popular nas redes de ensino, nos movimentos sociais e experiências de organização popular, a exemplo das iniciativas de economia solidária e de grupos culturais inseridos em diferentes contextos da sociedade brasileira.

É importante destacar que novas gerações de pesquisadores e militantes sociais vêm se aprofundando hoje na obra de Freire. Principalmente em um contexto de ataques à democracia e aos direitos sociais que infelizmente vivemos atualmente no Brasil. A obra de Freire e a memória desse grande educador reconhecido mundialmente também são atacadas injustamente até por autoridades da República. Esses ataques ocorrem, geralmente, sem um conhecimento mínimo dos escritos de Paulo Freire e de sua trajetória acadêmica. 
Mas, tais fatos e posturas, mesmo que nos entristeçam e nos envergonhem como brasileiros, por outro lado estimulam reações positivas no campo da educação progressista. A obra de Freire passou a ser mais consultada, discutida e referenciada nos espaços universitários e nos movimentos de educação popular Brasil afora. Esse fenômeno recente alimenta a esperança no futuro de uma educação mais crítica e humanizadora, na qual Paulo Freire é uma das referências importantes, mas não a única. Há vários parentescos intelectuais que reforçam a perspectiva de uma pedagogia crítica, progressista, democrática e engajada nas lutas pela construção de um mundo mais justo e humanizado. Esse é o horizonte das pesquisas analisadas no PPGE/UFRGS.

\section{CONSIDERAÇÕES FINAIS}

As repercussões das pesquisas desenvolvidas nos PPGEs da UFRGS e da Unipampa têm produzido importante impacto na formação de educadores, com os ensinamentos de Paulo Freire. A proposta não é reproduzir o pensamento freiriano, mas desenvolver pesquisas novas.

Percebe-se que as descobertas e os ensinamentos de Freire continuam atuais, arejando os trabalhos desenvolvidos nas instituições de pesquisa.

A participação de todos nas atividades da escola é fundamental para o pleno funcionamento escolar. Quando o grupo não acolhe a proposta da equipe diretiva, simplesmente os projetos não andam, porque dependem de todos os profissionais da escola, não apenas da equipe diretiva ou de um pequeno grupo.

A escola, como referência da ação coletiva, indica a própria qualidade da educação. Representa uma ação política, de lutas e esperanças. Por isso, deve ser cuidada e todos devem zelar pela sua pedagogicidade, pois há "eloquência do discurso pronunciado na e pela limpeza do chão, na boniteza das salas, na higiene dos sanitários, nas flores que adornam." (FREIRE, 2002, p. 50).

Com base nos resultados dos TCCs analisados, alguns aspectos devem estar presentes na elaboração das intervenções das escolas, aqueles que favorecem a participação dos professores: a opção pela organização social das atividades interventivas colaborativas, em detrimento das atividades competitivas ou individuais; a realização de leituras de trabalhos de pesquisa e o consequente debate coletivo; a valorização da escuta dos trabalhos didáticos desenvolvidos em sala de aula pelos professores da escola.

Os relatórios indicam a necessidade e importância do grupo para o desenvolvimento da educação. Este processo de integração pode comprometer a todos com a causa, pois "não há um sem os outros, mas ambos em permanente integração" (FREIRE, 1997, p. 20). 
O pensamento pedagógico freiriano traz como uma das características importantes da educação o fato de ser um ato de amor. Desenvolve sua proposta com o compromisso dos sujeitos participantes.

É vivendo, não importa se com deslizes, com incoerências, mas disposto a superá-los, a humildade, a amorosidade, a coragem, a tolerância, a competência, a capacidade ele decidir, a segurança, a eticidade, a justiça, a tensão entre paciência e impaciência, a parcimônia verbal, que contribuo para criar, para forjar a escola feliz, a escola alegre. (FREIRE, 1997, p. 42).

Freire (1997, p. 42) continua: "me entrego, disponivelmente, à alegria de viver. E é a minha entrega à alegria de viver, sem que esconda a existência de razões para tristeza na vida, que me prepara para estimular e lutar pela alegria na escola."

Os resultados das pesquisas, constatados nos trabalhos de conclusão, mostram novamente a importância da pesquisa na ação educativa para superar a educação bancária, denunciada por Freire (1983, p. 33) "como instrumento de opressão". Para o autor, o processo de formação humana se dá em um conjunto das ações coletivas, como educandos, educadores e comunidade, de modo todo especial, na gestão das práticas educativas e na gestão das políticas públicas da educação.

Para o conjunto da educação, o relatório também revela ações que contribuíram para modificar os altos índices de reprovação e evasão dos estudantes e fazer com que essas ações "funcionem efetivamente, principalmente no que diz respeito ao acompanhamento e monitoramento direto as escolas, e para isso vamos propor instrumentos claros e objetivos para fazer esse acompanhamento e monitoramento." (COSTA, 2014, p. 87).

A proposta do Mestrado Profissional em Educação tem como objetivo qualificar as práticas de profissionais que atuam na gestão de unidades escolares e na gestão da educação, revelada por Costa (2014, p. 104): “Destaco o aprendizado obtido, tanto por parte dos participantes, quanto desta pesquisadora; além de melhores práticas, que puderam ser obtidas com o Projeto de Intervenção e com a participação de todos."

O resultado do processo da intervenção proposta foi avaliado por uma participante que destacou "a importância de um trabalho em equipe, pois em todos os momentos discutimos, estudamos e encontramos em conjunto soluções para planejar este curso. Aprendi que para a formação na escola do campo precisamos conhecer sobre a realidade da escola, saber sobre a vida no campo." (FLORES, 2015, p. 61). Em outro momento a participante afirmou: "Somos 
capazes!!! Eu particularmente pretendo organizar uma turma com professores do campo para desenvolver o curso e poder discutir melhor com os colegas as alterações sugeridas." (p. 63).

Pelo depoimento avaliativo da autora, pode-se dizer que no decorrer do processo foram sendo construídas novas sínteses, novas estratégias, novas possibilidades que foram produzindo novas relações, instituindo novos espaços de interlocução. Entendemos que é no encontro, mesmo que inicialmente tutelado, que está o gérmen da tomada de consciência e que "quanto mais conscientizados nos tornamos, mais capacitados estamos para ser anunciadores e denunciadores." (FREIRE, 2001, p. 33).

Nos relatos dos trabalhos, encontramos recorrentemente afirmativas que nos levam a compreender que as pesquisas desencadeadas pelos mestrandos e mestrandas do curso de Mestrado Profissional em Educação constituem-se num fértil e prenhe processo de discussão, reflexão, crítica e novas elaborações do instituído. Dessa forma:

Com a formação as equipes gestoras foram desafiadas a elaborar, coletivamente, um planejamento de gestão, considerando que esta é a forma de garantir a estrutura organizacional da escola. As rotinas de planejamento e estudo eram consideradas apenas para cumprir uma exigência da mantenedora, atualmente, existem espaços destinados ao planejamento e sua execução como, por exemplo, a previsão no calendário escolar para estudos sistemáticos com encontros mensais entre as equipes diretivas e os professores, onde é tratado assunto essencialmente pedagógico, eliminando o caráter meramente administrativo que era observado nas reuniões nas escolas. A formação da equipe gestora abriu espaços para uma nova configuração de estudo coletivo na escola e, também fora dela como as formações subsequentes que estão acontecendo no município. (MACHADO, 2014, p. 121).

Conforme Freire (1983, p. 103), "esta investigação implica, necessariamente, numa metodologia que não pode contradizer a dialogicidade da educação libertadora”.

As discussões sobre a educação contemporânea exigem a avaliação contínua dos processos de ensino e aprendizagem. Os novos tempos requerem que as universidades se perguntem sobre a melhor forma de apresentar sua proposta curricular e o desenvolvimento do trabalho docente. Uma temática que normalmente aparece como proposta é a interdisciplinaridade ou, então, ter uma postura interdisciplinar. Esta se coloca como uma questão polêmica. Como ser interdisciplinar numa sociedade que se apresenta tão disciplinar? 
Os ensinamentos de Paulo Freire são retomados nos estudos sobre gestão das práticas educativas ou das políticas públicas, tendo presente a perspectiva interdisciplinar de sua obra. Sem dúvida, há muito a aprender e os programas de pós-graduação são espaços de aprofundamento e de diálogo.

\section{REFERÊNCIAS}

BRASIL. Portaria Normativa $\mathbf{n}^{\mathbf{0}} 17$ (Dispõe sobre o mestrado profissional no âmbito da Fundação Coordenação de Aperfeiçoamento de Pessoal de Nível Superior - CAPES) de 28 de dezembro de 2009. Disponível em: https://www. capes.gov.br/images/stories/download/legislacao/PortariaNormativa_17MP. pd. Acesso em: nov. 2021.

BRASIL. Conselhos Escolares: democratização da escola e construção da cidadania. Brasília: MEC/SEB, 2004. Disponível em: http://portal.mec.gov.br/ seb/arquivos/pdf/Consescol/ce_cad1.pdf. Acesso em: jun. 2021.

BRASIL. LDB - Lei de Diretrizes e Bases da Educação Nacional. Brasília: MEC, 2005. Disponível em: https://www2.senado.leg.br/bdsf/bitstream/ handle/id/70320/65.pdf?sequence=3. Acesso em: mai. 2021.

COMIN, Silene Gonçalves Silva. Formação acadêmico-profissional de professores do ensino médio: reflexões sobre a interdisciplinaridade e a contextualização na prática educativa. Relatório Crítico-Reflexivo. (mestrado em educação). Universidade Federal do Pampa, 2016. Disponível em: http://dspace. unipampa.edu.br:8080/jspui/handle/riu/1496. Acesso em jan. 2021.

COSTA, Angela Regina Pires. Avaliação institucional participativa na gestão regional da educação básica: $\mathrm{O}$ SEAP/RS na $35^{\mathrm{a}} \mathrm{CRE}$. Relatório CríticoReflexivo. (mestrado em educação). Universidade Federal do Pampa, 2014. Disponível em: http://dspace.unipampa.edu.br:8080/jspui/handle/riu/350. Acesso em jan. 2021.

FLORES, Elaine Aparecida Pereira. Um olhar crítico-construtivo sobre curso de formação do PROINFO integrado na educação do campo. Relatório Crítico-Reflexivo. (mestrado em educação). Universidade Federal do Pampa, 2015. Disponível em: http://dspace.unipampa.edu.br:8080/jspui/handle/ riu/400. Acesso: mai. 2021 
FREIRE, Paulo. Ação cultural para a liberdade e outros escritos. Rio de Janeiro: Paz e Terra, 1981.

FREIRE, Paulo. Pedagogia do oprimido. 17. ed. Rio de Janeiro: Paz e Terra, 1983.

FREIRE, Paulo. A importância do ato de ler: em três artigos que se completam. São Paulo: Autores Associados: Cortez, 1989.

FREIRE, Paulo. Conscientização teoria e prática da libertação: uma introdução ao pensamento de Paulo Freire. São Paulo: Centauro, 1996.

FREIRE, Paulo. Pedagogia da esperança: um reencontro com a pedagogia do oprimido. 17. ed. Rio de Janeiro; Paz e Terra, 1997.

FREIRE, Paulo. Professora sim, tia não: cartas a quem ousa ensinar. São Paulo: Olho d'Água, 1997.

FREIRE, Paulo. Pedagogia da indignação: cartas pedagógicas e outros escritos. São Paulo: Editora UNESP, 2000.

FREIRE, Paulo. Pedagogia da autonomia: saberes necessários à prática educativa. 25. ed. São Paulo: Cortez, 2002.

FREIRE, Paulo. Educação e mudança. Rio de Janeiro: Paz e Terra, 2010.

FREIRE, Paulo. Educação como prática de liberdade. São Paulo, 2011.

GREEN, Elliott. What are the most-cited publications in the social sciences (according to Google Scholar)? Publicado em maio de 2016. Disponível em: https://blogs.lse.ac.uk/impactofsocialsciences/2016/05/12/what-are-the-mostcited-publications-in-the-social-sciences-according-to-google-scholar/\#author. Acesso em mai. 20121.

IFSUL. Programa de Pós-graduação em Educação (PPGEDU). Página atualizada em 05/04/2021. Disponível em: http://www2.pelotas.ifsul.edu.br/ mpet/ . Acesso: mai. 2021 
IFSUL. Programa de Pós-graduação em Educação (PPGEDU). Página atualizada em 2019. Disponível em: http://pelotas.ifsul.edu.br/ensino/cursosstricto-sensu/copy_of_mestrado-profissional-em-educacao-e-tecnologia. Acesso: mai. 2021.

IFSUL. Repositório Institucional do IFSul. (Dissertações PPGEDU/ MPET, Campus Pelotas). Disponível em: http://omp.ifsul.edu.br/index.php/ repositorioinstitucional/catalog/category/dissertacoes . Acesso: mai. 2021.

MACHADO, Paula Vicentina Ferreira. Política de formação técnicopedagógica das equipes gestoras da educação no município de São SepéRS. Relatório Crítico-Reflexivo. (mestrado em educação). Universidade Federal do Pampa, 2014. Disponível em: http://dspace.unipampa.edu.br:8080/jspui/ handle/riu/356. Acesso: mai. 2021.

OLIVEIRA, Eliézer Dos Santos. O complexo do Trabalho como fundamento dos modelos ontológico-didáticos hegemônicos da educação capitalista vigente. 2016. Dissertação (Mestrado Profissional em Educação e Tecnologia) Instituto Federal Sul-Rio-Grandense (IFSul), Pelotas, 2016.

ROCHA, Nilson Duarte. A Educação ambiental na proposta pedagógica de uma escola de Ensino Fundamental: da incompletude ecológica á complexidade socioambiental. Relatório Crítico Reflexivo. Unipampa. 2016.

UNIPAMPA. Programa de Pós-Graduação em Educação. Relatório CríticoReflexivo. Disponível em: http://cursos.unipampa.edu.br/cursos/ppgedu/ relatorio-critico-reflexivo. Acesso: mai. 2021 


\section{Lúcio Jorge Hammes}

Professor dos cursos de licenciatura e do PPG em Educação da Universidade Federal do Pampa, Campus Jaguarão-Jaguarão, RS, Brasil.E-mail: luciohammes@ unipampa.edu.br

\section{Itamar Luís Hammes}

Professor do Instituto Federal de Educação, Ciência e Tecnologia Sulriograndense (IFSUIL) - Campus Lajeado e do Mestrado do Programa de Pósgraduação em Educação Profissional e Tecnológica (ProfEPT). Lajeado, RS, Brasil. E-mail: itamarh57@gmail.com

\section{Jaime José Zitkoski}

Professor do Programa de Pós-Graduação em Educação da Universidade Federal do Rio Grande do Sul. - Porto Alegre, RS, Brasil. E-mail: jaime.jose@ufrgs.br.

Recebido em: 20/04/2021

Aprovado em: 22/06/2021 